\title{
Tooth engineering: searching for dental mesenchymal cells sources
}

\author{
Laetitia Keller ${ }^{1,2+}$, Sabine Kuchler-Bopp ${ }^{1,2+}$, Soledad Acuña Mendoza ${ }^{3}$, Anne Poliard $^{3}$ and Hervé Lesot ${ }^{1,2 *}$ \\ UMR 977, Faculté de Médecine, INSERM, Strasbourg, France \\ 2 Faculté de Chirurgie Dentaire, Université de Strasbourg, Strasbourg, France \\ ${ }^{3}$ EA 2496, Faculté de Chirurgie Dentaire, Université Paris Descartes, Montrouge, France
}

\section{Edited by:}

Gianpaolo Papaccio, Second University

of Naples, Italy

\section{Reviewed by:}

Gianpaolo Papaccio, Second University of Naples, Italy

Eumorphia Remboutsika, Biomedical Sciences Research Centre "Alexander Fleming," Greece

\section{*Correspondence:}

Hervé Lesot, UMR 977, Faculté de Médecine, INSERM, 11, Rue Humann, 67085 Strasbourg Cedex, France. e-mail: lesot@unistra.fr

${ }^{\dagger}$ Laetitia Keller and Sabine KuchlerBopp have contributed equally to this work
The implantation of cultured re-associations between embryonic dental mesenchymal cells and epithelial cells from mouse molars at embryonic day 14 (ED14) allowed making full teeth with crown, root, periodontal ligament fibers, and bone. Although representing valuable tools to set up methodologies embryonic cells are not easily available. This work thus aimed to replace the embryonic cells by dental mesenchymal cell lines or cultured expanded embryonic cells, and to test their ability to mediate tooth development in vitro when re-associated with a competent dental epithelium. Histology, immunostaining and RT-PCR allowed getting complementary sets of results. Two different immortalized cell lines from ED18 dental mesenchyme failed in mediating tooth formation. The potentialities of embryonic dental mesenchymal cells decreased from ED14 to ED16 and were lost at ED18. This is likely related to a change in the mesenchymal cell phenotype and/or populations during development. Attempts to cultivate ED14 or ED16 embryonic dental mesenchymal cells prior to re-association led to the loss of their ability to support tooth development. This was accompanied by a down-regulation of Fgf3 transcription. Supplementation of the culture medium with FGF2 allowed restoring Fgf3 expression, but not the ability of mesenchymal cells to engage in tooth formation. Altogether, these observations suggest that a competent cell population exists in the dental mesenchyme at ED14, progressively decreases during development, and cannot as such be maintained in vitro. This study evidenced the need for specific conditions to maintain the ability of dental mesenchymal cells to initiate whole tooth formation, when re-associated with an odontogenic epithelium. Efforts to improve the culture conditions will have to be combined with attempts to characterize the competent cells within the dental mesenchyme.

Keywords: tooth, dental mesenchymal cells, mouse, FGF, culture, tissue engineering

\section{INTRODUCTION}

Cultured re-associations of murine embryonic dental epithelial and ecto-mesenchymal cells allow tooth formation in vitro (Hu et al., 2006a; Nakao et al., 2007). This included epithelial histogenesis and the formation of a functional primary enamel knot (PEK) after 3-4 days (Hu et al., 2005; Nakao et al., 2007), then driving cusps formation after 6 days (Hu et al., 2005). Finally odontoblasts differentiated, became functional, and thus could induce ameloblast differentiation. In both cases, gradients of differentiation were observed as in physiological conditions. After implantation of these cultured re-associations, the root development was initiated, and the dental mesenchyme and enamel organ became vascularized (Hu et al., 2006a; Nait Lechguer et al., 2008, 2011). This vascularization was an important step since it allowed further mineralization of the dentin and enamel in the crown. In the root, dentin, and cementum were secreted and periodontal ligament fibers formed, which interacted with the surface of root and extended toward newly formed bone (Hu et al., 2006a; Nait Lechguer et al., 2011). These data obtained with cells from embryonic day (ED) 14 first lower mouse molar represent a set of criterions to be satisfied with other cell sources if this experimental strategy has to be applied to whole tooth engineering. However, the preparation of embryonic cells from first lower molars at ED14 is time consuming and the number and frequency of experiments depend on having embryos at the right stage, which is not possible every day. Several murine cell sources, including ecto-mesenchymal cells prepared from late embryonic or adult teeth, immortalized or not, as well as bone marrow-derived cells have been tested in different experimental conditions (Young et al., 2002; Duailibi et al., 2004; Ohazama et al., 2004; Iwatsuki et al., 2006; Honda et al., 2007b, 2008; Yen and Sharpe, 2008; Arany et al., 2009; Huang et al., 2009). The goal of these complementary approaches was to engineer either a whole tooth or specialized dental tissues.

As a first step toward qualifying an easily available cell source, attempts were thus made to replace freshly isolated embryonic dental mesenchymal cells either by cell lines, or by in vitro-expanded cells from ED14 first lower molars. To this end, we analyzed the potentialities of two clonal dental mesenchymal cell lines derived from ED18 mouse first lower molars, when re-associated with an intact ED14 dental epithelium, known to be competent (Hu et al., 2005; Nakao et al., 2007; Honda et al., 2008; Arany et al., 2009). Both cell lines present an odontoblast gene signature (Priam et al., 2005), but17IA4 behaves as a multipotent cell progenitor capable of differentiating toward an odonto/osteoblast, chondroblast, or 
adipocyte phenotype upon appropriate induction, while 705IC5 displayed a more restricted potential (Lacerda et al., unpublished data). We also evaluated the potentialities of freshly isolated versus cultured embryonic dental ecto-mesenchymal cells obtained from ED14, ED16, and ED18 mouse first lower molars, to stimulate epithelial histogenesis and cell differentiation, when in contact with the competent epithelium.

\section{MATERIALS AND METHODS CLONAL DENTAL MESENCHYMAL CELLS}

Clonal mesenchymal cell lines (17IA4 and 705IC5), derived from ED18 mouse molars by limiting dilution, were characterized as previously described (Priam et al., 2005). These cells were cultured in DMEM/F12 (Gibco, Invitrogen, Cergy Pontoise, France) supplemented with L-glutamine (2 mM, Gibco, Invitrogen), 10\% fetal bovine serum (FBS, Gibco, Invitrogen), and penicillin/streptomycin (50 U/ml, Gibco, Invitrogen). The medium was changed every 2 days. In some experiments, FGF2 (2 ng/ml; PeproTech Inc., Rocky Hill, NJ, USA) was added to the culture medium. In this case, the culture medium was changed every day.

\section{EMBRYONIC DENTAL MESENCHYMAL CELLS}

First lower molars were dissected from ICR mice (Charles River Laboratories, L'Arbresle, France) embryos at ED14, ED16, and ED18 (the vaginal plug day was determined as ED0). All procedures were in compliance with the recommendations of the European Economic Community (86/609/CEE) on use and care of laboratory animals.

The dental epitheliums and mesenchymes from ED14, ED16, and ED18 mouse molars were dissociated by using 1\% trypsin (Difco, BD Biosciences, Le Pont-de-Claix, France) in DMEM/F12 culture medium at $4^{\circ} \mathrm{C}$ for $30 \mathrm{~min}$. The absence of contamination of any tissue by the other was checked from histological sections as previously described (Hu et al., 2006a). The mesenchymes were further dissociated, filtrated in order to get single cells, and suspended in MEM (Gibco, Invitrogen) containing 20\% FBS (Cambrex Bio Science Verviers SPRL, Verviers, Belgium), penicillin/streptomycin (50 U/ml, Gibco, Invitrogen), and L-glutamine (2 mM, Gibco, Invitrogen; Hu et al., 2005). The cells were either immediately used for re-association or cultured for 4 days before re-association. In some experiments, the dental mesenchymal cells from ED14 were cultured for 1 or 4 days in the presence of FGF2 ( $2 \mathrm{ng} / \mathrm{ml}$; PeproTech Inc.) before their re-association with a dental epithelium. For theses experiments, the culture medium was changed every day.

\section{RE-ASSOCIATIONS AND IN VITRO CULTURE}

Clonal mesenchymal cells 17IA4 and 705IC5 were re-associated with an intact ED14 epithelium (28 re-associations for 17IA4 and 21 re-associations for 705IC5). Further re-associations were performed with 17IA4 cells $(n=18)$ and 705IC5 $(n=17)$ after these cells had been pre-cultured for 4 days in the presence of FGF2.

Epithelium of ED14 was re-associated with freshly dissociated mesenchymal cells of ED14 (81 re-associations), ED16 (15 re-associations), and ED18 (16 re-associations) or with mesenchymal cells cultured for 4 days before re-association with ED14 epithelium $(66,62$, and 11 re-associations for cultured ED14, ED16, and ED18 respectively). Dental mesenchymal cells from ED14 have been cultured for 4 days in the presence of FGF2, before they were re-associated with an ED14 dental epithelium (38 re-associations).

Re-associations between cloned cell lines or embryonic mesenchymal cells and dental epitheliums from ED14 have been cultured for 2, 4, 6, 8, and 10 days as previously described (Hu et al., 2005) on a semi-solid medium which consisted of DMEM/F12 (Gibco, Invitrogen), containing 20\% FBS (Cambrex Bio Science Verviers SPRL, Verviers, Belgium) and supplemented with ascorbic acid (0.10 mg/ml, Merck, Darmstadt, Germany), L-glutamine (2 mM, Gibco, Invitrogen), penicillin/streptomycin (50 U/ml, Gibco, Invitrogen), and agar (0.36\%, Sigma-Aldrich Chimie SARL, Lyon, France). Cultures were incubated at $37^{\circ} \mathrm{C}$ in a humidified atmosphere of $5 \% \mathrm{CO}_{2}$. The medium was changed every 2 days.

\section{IN VIVO IMPLANTATION}

Re-associations between 17IA4 and 705IC5 cells with dental epitheliums from ED14 were cultured for 2 days prior to their implantation between skin and muscles behind the ears in 8 weeks old mice according to $\mathrm{Hu}$ et al. (2006a). The implants were maintained up to 2 weeks.

\section{IMMUNOFLUORESCENCE AND HISTOLOGY}

Implanted re-associations between 17IA4 cells/epithelium 14 and 705IC5 cells/epithelium 14 were embedded in Tissue-Tek. Serial frozen sections $(7 \mu \mathrm{m})$ were stained with polyclonal rat anti-CD31 (1/100) (BD Pharmingen, Evry, France) for the detection of vascular endothelial cells (Nait Lechguer et al., 2008), with polyclonal rabbit anti-aggrecan (1/100; Santa Cruz, Tebu-bio, Le Perray-enYvelines, France) for detection of cartilage and with polyclonal rabbit anti-osteopontin (1/200; Santa Cruz, Tebu-bio) for detection of bone. After washing with PBS, sections were incubated with secondary anti-rat or anti-rabbit antibodies conjugated to Alexa 594 (Molecular Probes, Invitrogen).

For histology, samples were fixed in Bouin-Hollande, embedded in paraffin and $5 \mu \mathrm{m}$ serial sections were stained with Mallory.

\section{RNA ISOLATION AND RT-PCR ANALYSIS}

RT-PCR was performed on dental mesenchymal cells from ED14, ED16, and ED18 mouse molars, just after the tissue dissociation or after they have been cultured for 4 days, and on 17IA 4 cells. Similar analysis were performed on ED14 dental mesenchymal cells, 17IA4 and 705IC5 cells cultured for 1 or 4 days in the presence of FGF2. Total RNA was isolated by affinity chromatography using the RNeasy ${ }^{\circledast}$ Minikit (Qiagen Inc., Hilden, Germany) and reversetranscribed with oligo (dT) ${ }_{12}$ and Superscript III (Invitrogen), according to the manufacturer protocols. In each experiment $1 \mu \mathrm{g}$ of total RNA was used for RT in a final reaction volume of $20 \mu \mathrm{l}$, $1 \mu \mathrm{l}$ being used for PCR. PCR amplification was carried out with the Go Taq Hot Start kit (Promega, Charbonnières-les-Bains, France) according to the manufacturer's instructions, using the specific primers listed in Table 1. PCR conditions were as followed: initial denaturation of $3 \mathrm{~min} 94^{\circ} \mathrm{C}$ followed by 35 cycles at $94^{\circ} \mathrm{C}$ for $1 \mathrm{~min}$, annealing for $1 \mathrm{~min}$ and elongation for $1 \mathrm{~min}$ at $72^{\circ} \mathrm{C}$, with a final extension of $10 \mathrm{~min}$ at $72^{\circ} \mathrm{C}$. PCR products were separated by electrophoresis on $1.5 \%$ agarose gels. Primer sequences, annealing temperatures and size of amplified products are listed in Table 1. 
Table 1 | Sequences of the primers used in RT-PCR analysis, size of the amplified products and annealing temperatures.

\begin{tabular}{|c|c|c|c|c|}
\hline Gene transcript & Annealing $\mathrm{T}\left({ }^{\circ} \mathrm{C}\right)$ & Sense primer & Antisense primer & Size (bp) \\
\hline GAPDH & 58 & TGAAGGTCGGTGTGAACGGATTTGGC & CATGTAGGCCATGAGGTCCACCAC & 1000 \\
\hline Lhx6 & 55 & CGACGACATCCACTACTCTCCGT & CAAGCTGAATTAGCCATTGCTCC & 430 \\
\hline Pax9 & 60 & GCATCCGCTCCATCACCGACC & TGGACGCTCCCATCAGAGTGC & 433 \\
\hline Dlx5 & 60 & CAGAAGAGTCCCAAGCATCC & GAGCGCTTTGCCATAAGAAG & 193 \\
\hline Bmp2 & 59 & CTGCAGCAAGAACAAAGCAG & GAGGGCCCACAAGATAATCA & 206 \\
\hline Bmp4 & 55 & CCAGAGAATGAGGTGATCTCC & TGGCAGTAGAAGGCCTGGTAG & 569 \\
\hline Fgf3 & 59 & GCAAGCTCTACTGCGCTACC & TGCGTTGTAGTGATCCGAAG & 203 \\
\hline Fgf10 & 59 & GTCAAAGCCATCAACAGCAA & СTCTCCTGGGAGCTCCTTTT & 199 \\
\hline
\end{tabular}

\section{RESULTS}

\section{CLONAL MESENCHYMAL CELLS FROM ED18 MOUSE MOLARS}

Two different clonal dental mesenchymal cell lines (17IA4, 705IC5) have been tested. The observations made with these cells were compared with the results obtained when using dental mesenchymal cells from ED14 molars as control, as already shown to allow tooth development (Hu et al., 2006a; Nait Lechguer et al., 2008).

After 2 days for both clonal cell lines, only round mesenchymal cells were present at the epithelial-mesenchymal junction (Figures 1E,I) and there was no sign of epithelial histogenesis. At the same stage of culture, when using ED14 dental mesenchymal cells, the epithelial-mesenchymal junction was restored and a discrete stellate reticulum (SR) was interposed in between the inner dental epithelium (IDE) and outer dental epithelium (ODE; Figure 1A).

After 4 days, re-associations made with 17IA4 or 705IC5 cell lines did not display any typical dental epithelial histogenesis (Figures 1F,J), whereas when using embryonic dental mesenchymal cells, the PEK and the SR were clearly visible (Figure 1B).

After 6 days, re-associations with clonal mesenchymal cells did not show any progress with epithelial histogenesis (Figures 1G,K), indicating that the absence of a PEK after 4 days was not simply a matter of delay. Although initially present at the onset of the re-association, the PEK could not be maintained in these experimental conditions. After 6 days, in re-associations made with ED14 mesenchymal cells, secondary enamel knots (SEK) were present at the tip of the cusps (Figure 1C). However, the mesenchymal cells in contact with the epithelium still remained as round undifferentiated preodontoblasts (Figure 1C).

After 10 days, when using cloned dental mesenchymal cells, crown morphogenesis was not achieved (not shown). There was no odontoblast differentiation and disruptions of the epithelialmesenchymal junction were observed with both 17IA4 and 705IC5 cell lines (Figures 1H,L). In contrast, with the embryonic dental cells, odontoblasts differentiated (Figure 1D), they elongated, polarized, and became functional, accumulating predentin at the epithelial-mesenchymal junction (Figure 1D).

Since neither 17IA4 nor 705IC5 cell line could lead to tooth-like differentiation when cultured in association with an ED14 dental epithelium, attempts were made to implant these re-associations after an initial culture for 2 days. This pre-culture allowed the epithelial-mesenchymal junction to be restored. After 2 weeks, both types of implants were vascularized (Figures 2A,F), as also revealed by immunostaining for CD31, a marker for endothelial cells (Figures 2B,G). However, there still was no sign of tooth formation. Both cell types secreted matrices with different histological aspect (compare Figure 2C with Figure 2H). Differences in the extracellular matrix were further documented by immunostaining. Indeed, the matrix produced by 17IA4 cells was strongly positive for osteopontin (Figure 2E) and remained negative for aggrecan (Figure 2D). Conversely, the matrix produced by 705IC5 cells was positive for aggrecan (Figure 2I) and showed a very weak signal for osteopontin (Figure 2J).

The implantation of cultured re-associations did not allow improving the potentialities of clonal ecto-mesenchymal cell lines to stimulate tooth histo-morphogenesis in vitro.

\section{IMPORTANCE OF EMBRYONIC AGE TO PREPARE DENTAL ECTO- MESENCHYMAL CELLS}

The absence of tooth formation as observed with cloned cell lines, while prepared from ED18 dental papillae, raised the question of maintenance/loss of cell potentialities during tooth development. Dental ecto-mesenchymal cells were therefore prepared from ED16 and ED18 mouse first lower molars and compared to those from ED14, after re-association with an intact dental epithelium from ED14 (Figure 3).

In the re-associations performed with ED14 dental mesenchymal cells, only preodontoblasts were present at the epithelialmesenchymal junction after 6 days (Figures $1 \mathrm{C}$ and $3 \mathrm{~A}$ ). In the epithelium, cells of the stratum intermedium (SI) were visible (Figure 3A). After 10 days, odontoblasts became functional and secreted predentin while ameloblasts started to polarize (Figure 3B).

When dental mesenchymal cells from ED16 were used for reassociation, functional odontoblasts were present after 6 days in culture (Figure 3C). Gradients of differentiation were observed (data not shown). At this stage, the epithelial histogenesis was fully achieved in $75 \%$ cases after 6 days, showing the IDE, the ODE and the SI, which interacted with elongated and polarized ameloblasts (Figure 3D). However, the tooth morphology did not show the presence of several cusps, which could be expected at that stage. Tooth formation was initiated in $26 \%$ of the re-associations, when using mesenchymal cells from ED16, instead of 52\% when using mesenchymal cells from ED14. 

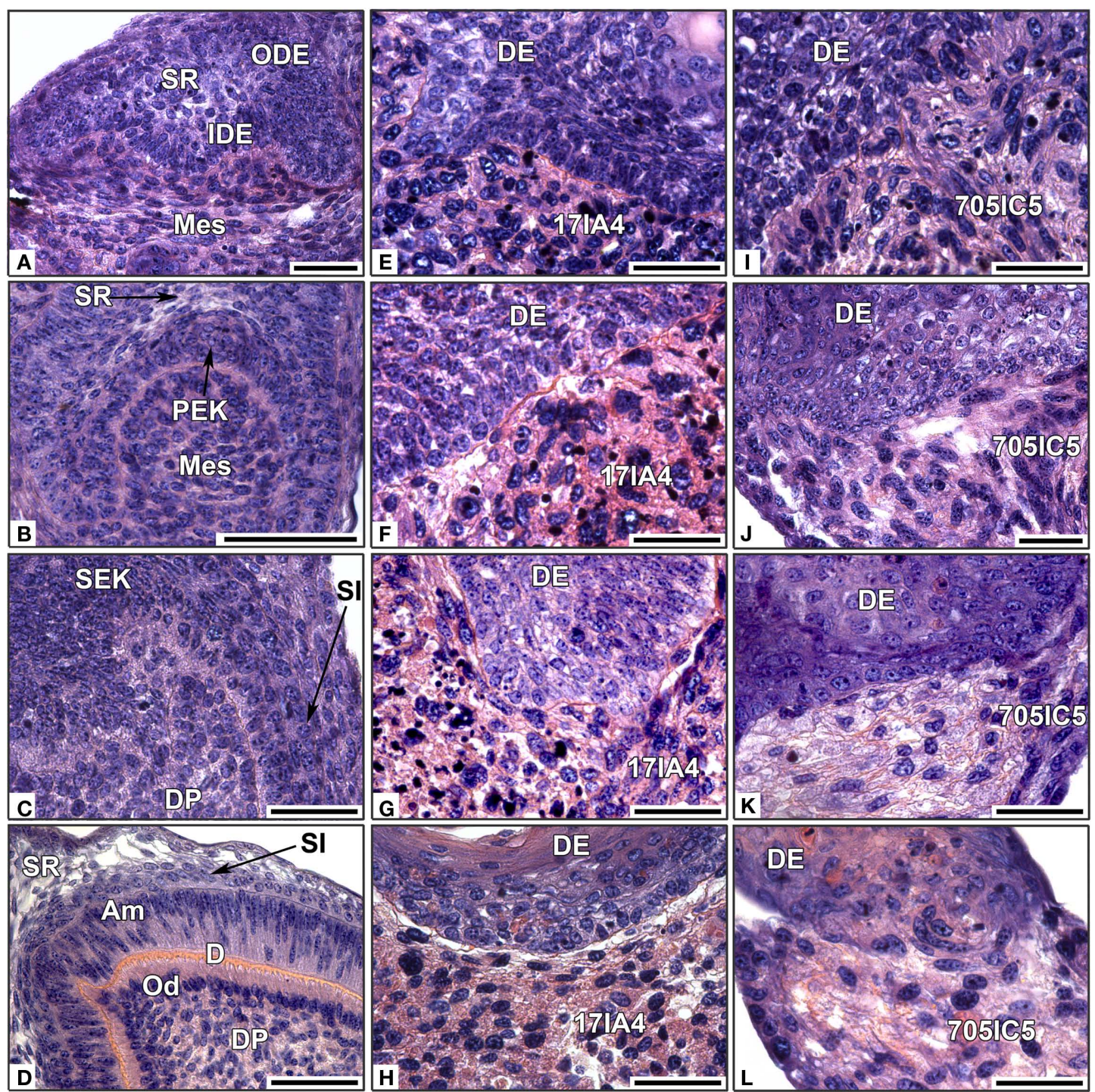

FIGURE 1 | In vitro re-associations between intact ED14 dental epithelium and dissociated single dental mesenchymal cells. The epitheliums were re-associated with dissociated mesenchymal cells from ED14 first lower molars (A-D), or with cloned ED18 dental mesenchymal cells 17IA4 (E-H) or 705IC5 (I-L). The re-associations were cultured for 2 days

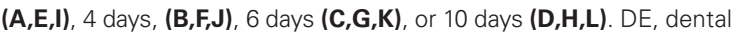
epithelium; DP, dental papilla; IDE, inner dental epithelium; Mes, mesenchyme; ODE, outer dental epithelium; PEK, primary enamel knot; SEK, secondary enamel knot; SI, stratum intermedium; SR, stellate reticulum; Od, odontoblast; PAm, preameloblast. Bars $=40 \mu \mathrm{m}$
When mesenchymal cells from ED18 were re-associated with an epithelium from ED14, an epithelial-mesenchymal junction was visible after 2 days (Figure 3E). However, epithelial histogenesis or cell differentiation was never observed after 6 days (Figure 3F). Instead, the dental epithelium keratinized (Figure 3F).

These experiments showed that the potentialities of embryonic dental ecto-mesenchymal cells diminished when the development progressed, suggesting a decrease in the number of competent cells.

\section{EFFECT OF A PRELIMINARY CULTURE OF DENTAL CELLS PRIOR TO RE-ASSOCIATION}

A second possibility to explain the negative results obtained with the two clonal cell lines could be linked to their culture and the multiple passages required for their cloning. To test a possible effect of the culture, dental mesenchymal cells were prepared from ED14, ED16, and ED18 mouse first lower molars, and cultured for 4 days prior to re-association with an epithelium from ED14 (Figure 4).

Cultured dental mesenchymal cells from all three stages failed to support tooth development when re-associated with an ED14 enamel organ (Figures 4B,E,H). Indeed, despite the maintenance of an epithelial-mesenchymal junction, no sign of epithelial histogenesis was detected after 2 days (Figures 4A,D,G) or 6 days (Figures 4C,F,I).

Cultured dental mesenchymal cells from ED14 and ED16 produced much more extracellular matrix that their non-cultured counterparts (compare Figure 4 with Figure 3). This matrix deposition increased with time (compare Figure $4 \mathrm{D}$ with Figures $4 \mathrm{E}, \mathrm{F}$ at 


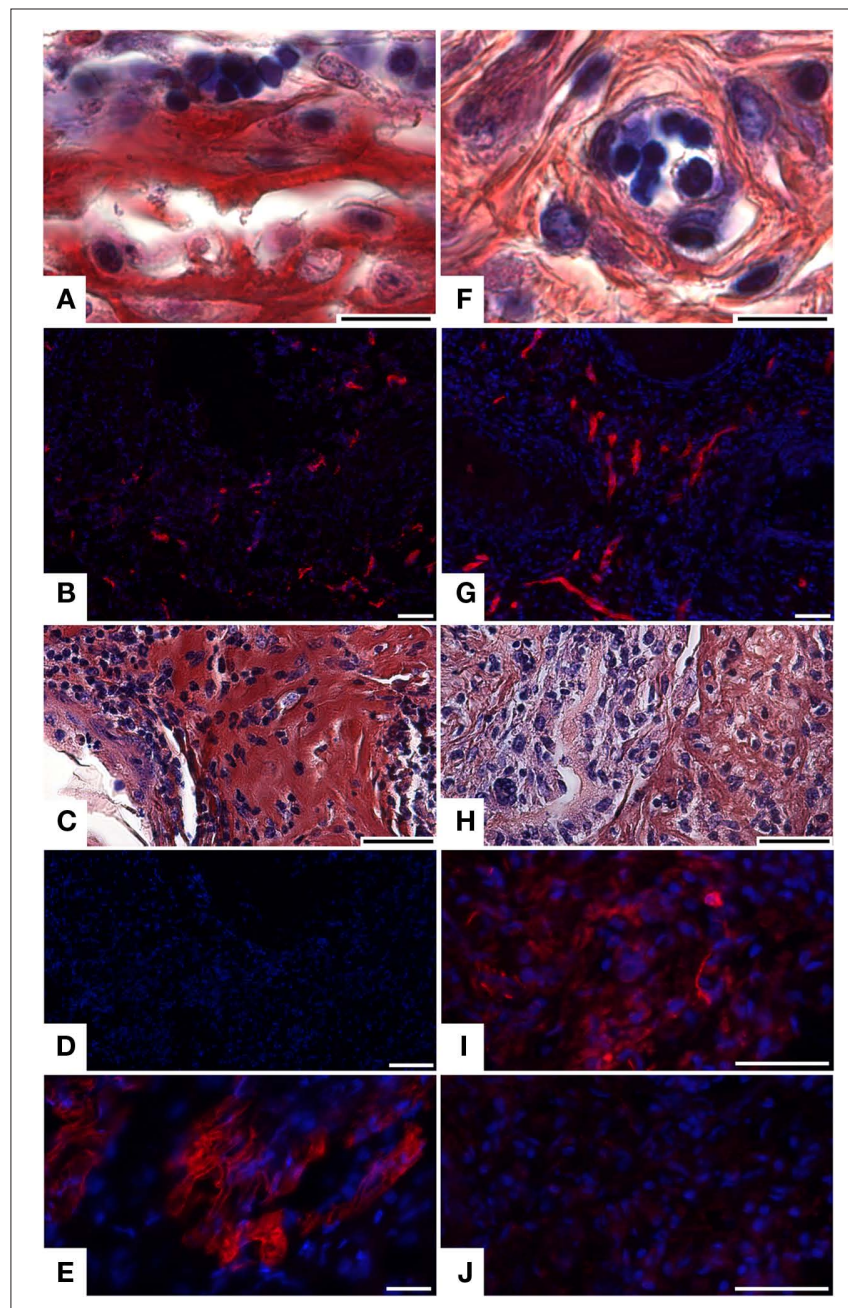

FIGURE 2 | Implantation of cultured re-associations between clonal dental mesenchymal cell lines and intact ED14 dental epithelium. After 2 days in vitro, re-associations performed with 17IA4 (A-E) and 705IC5 (F-J) clonal cell lines were implanted under the skin of a mouse for 2 weeks. Histology showed the presence of blood vessels in the two types of implants $(\mathbf{A}, \mathbf{F})$, which was confirmed by immunostaining for $\operatorname{CD} 31(\mathbf{B}, \mathbf{G})$. Histological sections suggested differences in the extracellular matrix secreted by the two cell lines $\mathbf{( C , H )}$. Immunostainings for aggrecan (D,I) and for osteopontin $\mathbf{( E , J ) ~ s h o w e d ~ d i f f e r e n t i a l ~}$ antigenicity, in the matrix secreted by $17 \mid \mathrm{A} 4$ (C-E) and by $705 \mathrm{IC5}$ (H-J) Bars $=10 \mu \mathrm{m}(\mathbf{A}, \mathbf{F}),=20 \mu \mathrm{m}(\mathbf{E}),=40 \mu \mathrm{m}(\mathbf{C}, \mathbf{G}-\mathbf{J}),=80 \mu \mathrm{m}(\mathbf{B}),=100 \mu \mathrm{m}$ (D).

ED16 or Figure 4G with Figures 4 H,I at ED18) and with the age of the embryos used to prepare the mesenchymal cells (compare Figure 4C with Figures 4F,I).

These experiments clearly showed that cultured cells loose their ability to stimulate tooth formation after re-association with a competent epithelium. The culture prior to re-association also led to a change in the phenotype of the mesenchymal cells, as seen from their accumulation of extracellular matrix.

\section{GENE EXPRESSION ANALYSIS IN FRESHLY PREPARED VERSUS CULTURED MESENCHYMAL CELLS}

The expression of several genes, known to be involved in tooth development, was analyzed by RT-PCR in freshly dissociated and cultured dental mesenchymal cells from ED14, ED16, and ED18 molars. At all stages, freshly prepared and cultured cells expressed Pax9, Dlx5, Lhx6, Lhx7, Msx1, Msx2, Bmp2, Bmp4, and Fgf10. Notably, at all three stages, the expression of Fgf3 transcripts was drastically down regulated in the cultured cells (Figure 5, lanes 2, 4, 6), compared to freshly prepared cells (Figure 5, lanes 1, 3, $5)$. The pattern of gene expression observed in the pulpal clone 17IA4 (Figure 5, lane 7) was similar to that in cultured embryonic mesenchymal cells.

\section{EFFECTS OF FGF2 ON CULTURED MESENCHYMAL CELLS}

Several groups have suggested that FGF2 might affect the properties of cultured dental mesenchymal cells. To test this possibility, dissociated ED14 dental mesenchymal cells as well as 17IA4 and 705IC5 cells were cultured in the presence of FGF2 and tested for their expression of Fgf3 and ability to support tooth development.

Fgf3 expression was restored in cultured ED14 dental mesenchymal cells when FGF2 was added to the medium for 1 day (Figure 6A, lane 3) or 4 days (Figure 6A, lane 5), compared to the same cultures performed without FGF2 (Figure 6A, lanes 2 and 4 respectively). However, these conditions did not allow the cultured mesenchymal cells to regain their capacity to stimulate tooth development in re-association (Figure 6B).

FGF2 had no effect on clonal cell lines, neither to stimulate Fgf3 expression (Figure 6A, lanes 6-9), nor to restore a functional dental epithelial-mesenchymal junction in re-association (compare Figure 6C with Figure 1H and Figure 6D with Figure 1L). However, FGF2 increased matrix production in 17IA4 cells (compare Figure 6C with Figure $1 \mathbf{H}$ ).

Fgf3 expression in ED14 dental mesenchymal cells was stimulated by FGF2. However, this was not sufficient to restore the ability of these cells to support tooth development.

\section{DISCUSSION}

While dental embryonic cells can be used to set up a methodology allowing complete tooth engineering (Hu et al., 2005, 2006a; Nakao et al., 2007; Nait Lechguer et al., 2008, 2011), new cell preparations for each experiment are time consuming and the amount of cells is often limiting the number of experiments. Attempts were thus made to use more easily available cell sources such as cell lines or culture expanded embryonic cells. Although this is required for both the epithelial and ecto-mesenchymal components of the tooth, as a first step, only the mesenchyme was taken into account.

\section{USE OF TWO CLONAL MESENCHYMAL CELL LINES}

In view of replacing the ecto-mesenchymal cell compartment, two different clonal dental mesenchymal cell lines, prepared from mouse molars at ED18, were tested: 17IA4 and 705IC5 (Priam et al., 2005). Despite their dental ecto-mesenchymal origin and odontoblast progenitor signature (Priam et al., 2005), the two clones tested in this work failed to initiate tooth development, when re-associated with a competent dental epithelium. An epithelial-mesenchymal junction was rapidly reconstituted, but the characteristics of a dental epithelial histogenesis, visible at ED14, was rapidly lost in the cultured re-associations and neither odontoblasts nor ameloblasts differentiated. 

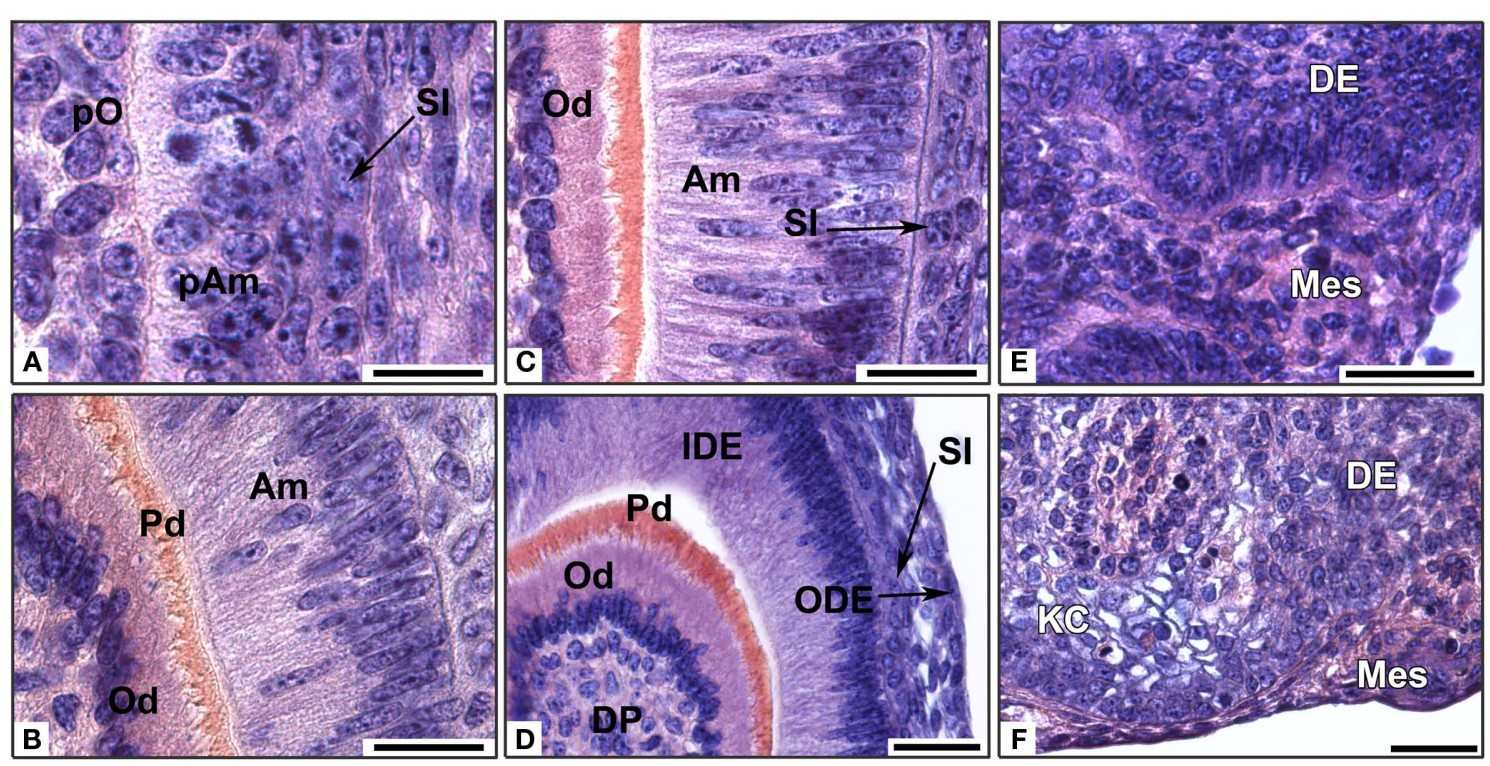

FIGURE 3 | In vitro development of re-associations between an ED14 intact dental epithelium and dissociated dental mesenchymal cells from different embryonic stages. Dental epitheliums were re-associated with mesenchymal dental cells from embryonic days 14 (A,B), 16 (C,D), or 18 (E,F). The re-associations were cultured for 2 days (E), 6 days $(\mathbf{A}, \mathbf{C}, \mathbf{D}, \mathbf{F})$, or
10 days (B). Am, ameloblast; DE, dental epithelium; DP, dental papilla; IDE, inner dental epithelium; KC, keratinized cyst; Mes, mesenchyme; Od, odontoblast; ODE, outer dental epithelium; pAm, preameloblast; $\mathrm{Pd}$, predentin; pO, preodontoblast; SI, stratum intermedium. Bars $=20 \mu \mathrm{m}$ (A-C) and $40 \mu \mathrm{m}$ (D-F).
Previous reports have shown that dental mesenchymal cells from ED18.5 after long-term culture and multiple passages could form teeth when re-associated with an enamel organ from ED14.5 and implanted for 2 weeks in subrenal capsule (Arany et al., 2009). These results might thus appear conflicting with ours. However, Arany et al. (2009) cultured cells in the presence of FGF2. This factor has been reported to help in maintaining the specific properties of different progenitor cell types. For example, hESC-derived neuronal progenitors were found to retain their full capacity to generate dopamine neurons after repeated passaging in the presence of FGF2 (Morizane et al., 2010). FGF2 has been shown to increase the lifespan and potential for differentiation of mesenchymal stem cells from the bone marrow (Bianchi et al., 2003). In cultured human dental pulp cells, FGF2 increases the ratio of Stro-1 positive stem cells (Morito et al., 2009). It was also found to stimulate the functional differentiation of odontoblasts and ameloblasts (Russo et al., 1998; Tsuboi et al., 2003), but indirectly by modulating the effects of TGF $\beta 1$ (Unda et al., 2000). The results obtained by Arany et al. (2009) suggest that (1) cell culture and passages are not impairing their use for tooth engineering, provided that this is done in the presence of FGF2 and (2) it is possible to restore the heterogeneity of a dental papilla after implantation of re-associations with a single type of cloned mesenchymal cells, which is more surprising. One possibility would be that the cloned cells could initiate tooth re-formation and then stem cells from the host could participate in further stages (Chai et al., 2000; Nait Lechguer et al., 2008; Rothova et al., 2011). Besides allowing tissue oxygenation and dental matrices mineralization (Nait Lechguer et al., 2008, 2011), the vascularization of implanted cell-cell re-associations might thus participate in other aspects of odontogenesis. To test this possibility, re-associations between 17IA4 or 705IC5 cells and an ED14 dental epithelium were implanted for 2 weeks. However, even in these conditions where re-vascularization occurred, no dental tissue developed.

The fact that 17IA4 and 705IC5 cell lines cannot engage in tooth development probably results from their inability to specify a dental epithelial-mesenchymal junction during the early stages of the re-association. Similar observations were reported when reassociating dental mesenchymes from ED18 with dental epitheliums from ED13 or even ED15 (Ruch and Karcher-Djuricic, 1971, see Figures 10 and 11). There was a too important stage difference between the two interacting tissues.

\section{CHANGES IN THE POTENTIALITIES OF DENTAL MESENCHYMAL CELLS DURING DEVELOPMENT}

To test a possible change in cell potentialities during development, re-associations were performed between a competent enamel organ from ED14 and dental mesenchymal cells at different stages. The capacity of dental mesenchymal cells to stimulate the development of tooth-like structures decreased from ED14 to ED16, and was lost at ED18.

Although the histological organization in the dental papilla is much less visible than in the enamel organ, several cell types are also present there. They include odontoblasts and the sub-odontoblast cell layer, blood vessels stem cells, associated to the blood vessels or not and nerves at late stages. It has been shown also that cells with a mesodermal origin could participate in the dental papilla formation, being brought through vascularization (Chai et al., 2000; Rothova et al., 2011). This cellular heterogeneity changes during development, and this might explain the progressive loss of potentialities that we observed. Similar changes have been reported recently when comparing mesenchymal cells from unerupted and erupted 


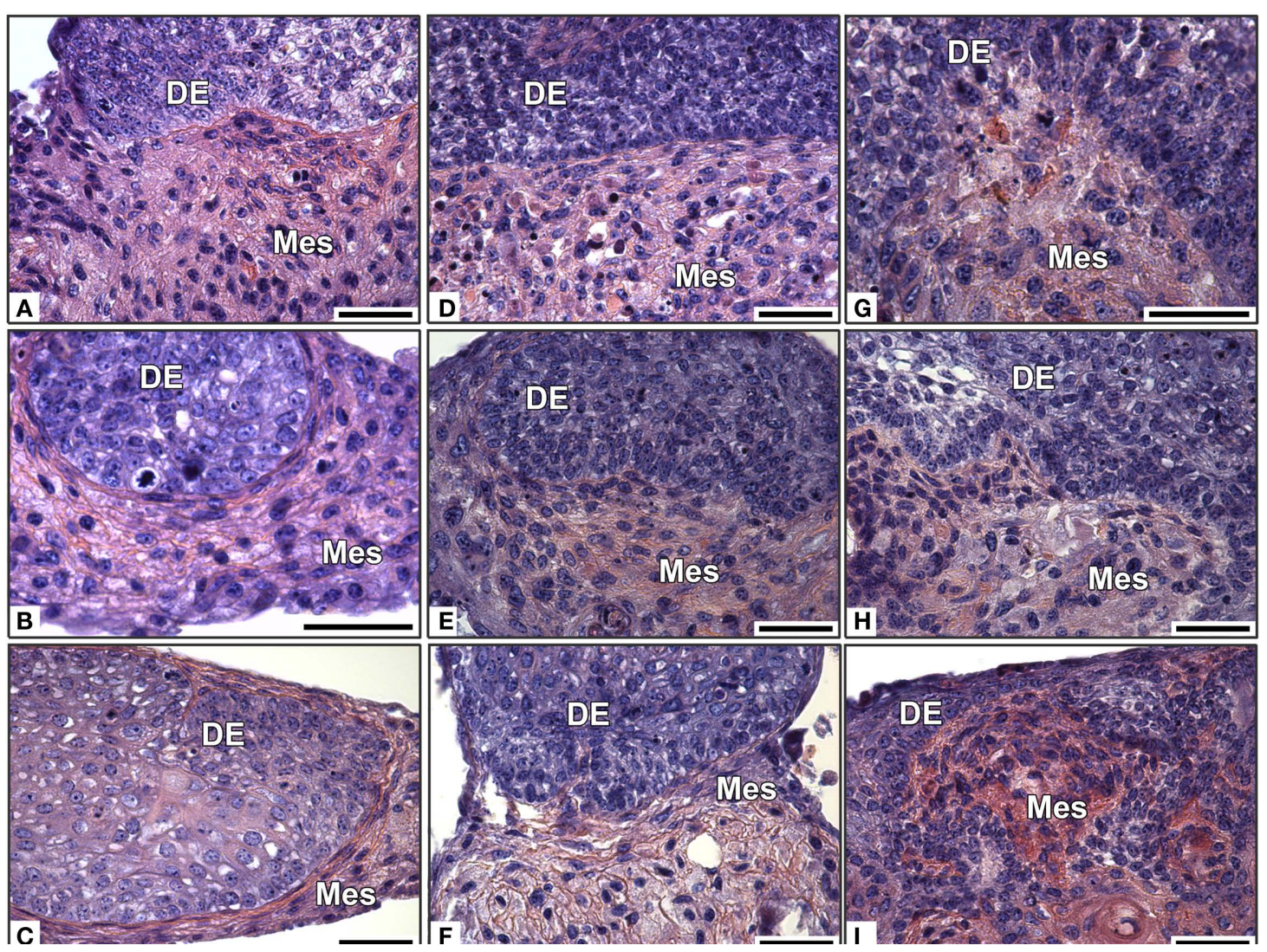

FIGURE 4 | In vitro development of re-associations between an intact ED14 dental epithelium and cultured dissociated dental mesenchymal cells from different embryonic stages. Dental epitheliums were re-associated with cultured dental cells from ED14 (A-C), 16 (D-F), or 18 (G-I). The re-associations were cultured for 2 days $(\mathbf{A}, \mathbf{D}, \mathbf{G}), 4$ days, $\mathbf{( B , E , H )}$, or 6 days $(\mathbf{C}, \mathbf{F}, \mathbf{I})$. DE, dental epithelium; Mes, mesenchyme. Bars $=40 \mu \mathrm{m}$. mouse molars (Balic et al., 2010). The proportion of mesenchymal cells able to engage in tooth re-formation in our experimental conditions may thus diminish as the development progresses from ED14 to ED16, and becomes too small at ED18 to allow tooth formation. Competent dental mesenchymal cells from ED18 and later stages would then need to be enriched or cloned in order to be used for tooth engineering.

Postnatal dental pulp cells have been isolated from either rat, pig, or human and tested for their potential to differentiate toward an odonto/osteogenic program (Huang et al., 2009) and to contribute to dental pulp tissue formation (Batouli et al., 2003; Duailibi et al., 2004; Cordeiro et al., 2008; Iohara et al., 2009; Sakai et al., 2010). At present, they probably constitute the best candidate cell population to be used in tooth engineering. However, up to now only one group has reported on their capacity to participate in the generation of a bioengineered tooth germ (Honda et al., 2007b). Different stem cell populations appear to co-exist in the human pulp, as suggested by their distinct differentiation potentials in vitro or in vivo (Gronthos et al., 2000; Laino et al., 2005; Kerkis et al., 2006; Iohara et al., 2009), but nothing is known about their possible relationship with the embryonic cells tested in this study. Another potential pitfall using postnatal dental pulp stem cells for tooth tissue engineering is that, like embryonic cells, they can show alterations or loss of their potentialities during expansion in vitro (Wagner et al., 2010).

\section{LOSS OF POTENTIALITIES IN VITRO}

When cultured for 4 days only and without passage, the dental mesenchymal cells from ED14 and ED16 were no longer able to induce the formation of tooth-like structures. This loss of potentialities occurred very rapidly since it was already observed after $24 \mathrm{~h}$ in vitro (data not shown). It might reflect a change in the phenotype and/ or in the heterogeneity of the mesenchymal cells, possibly due to an in vitro selection (Patel et al., 2009; Yu et al., 2010). Similarly, loss of cell potentialities in vitro has been reported for SP (side population) cells, considered to be primitive stem cells within the hematopoietic system (Challen and Little, 2006; Johnnidis and Camargo, 2008). SP cells were detected in adult porcine and human dental pulp (Iohara et al., 2006; Honda et al., 2007a). This SP cell fraction, which does not seem to be a single homogeneous one, could not be maintained in vitro (Honda et al., 2007a). Bone marrow cells have also been used for tooth engineering (Ohazama et al., 2004; Hu et al., 2006b). Their culture and passaging also had consequences on their phenotype (Igarashi et al., 2007; Halfon et al., 2011).

As a first step to search for possible changes in gene expression, which could be induced by the culture, RT-PCR was performed on dental mesenchymal cells to analyze the expression of several transcription factors (Pax9, Dlx5, Lhx6, Lhx7, Msx1, Msx2) and signaling molecules (Bmp2, Bmp4, Fgf3, and Fgf10), all involved in tooth development. All the genes selected for this initial approach were still 


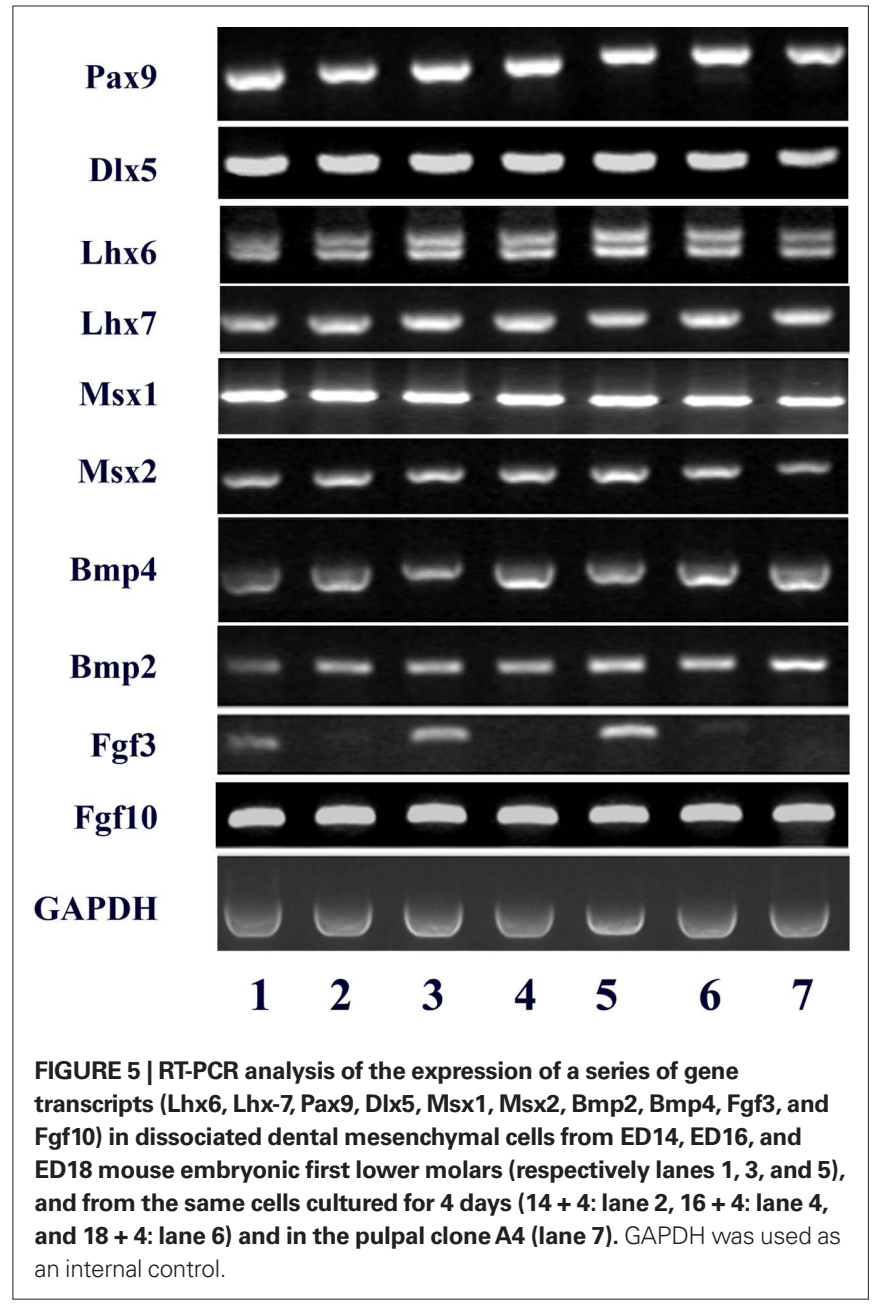

expressed by cultured cells, except for Fgf3, which was drastically down regulated upon culture. Mesenchymal FGF3 has been suggested to act on the epithelium (Kettunen et al., 2000; Nakatomi et al., 2010). Since FGF1, FGF2, and FGF8 can induce Fgf3 expression in the mesenchyme (Bei and Maas, 1998), these FGFs will have to be tested on cultured mesenchymal cells. Preliminary experiments showed that FGF2 allowed an up-regulation of Fgf3 expression in cultured ED14 dental mesenchymal cells, but not to restore their potentiality to engage in tooth formation when re-associated with a competent dental epithelium. FGF1 and FGF8 will have to be further investigated.

Recently, it was shown that stem cells environment might determine their behavior (Discher et al., 2009; Govindasamy et al., 2010; Li et al., 2010). This might apply to dental mesenchymal cells as well and allow a modulation of their activities during physiological tooth development. A transient change in these conditions, when cells are dissociated, might be much easier to restore after immediate re-association than after a period of culture in vitro, when cells have reorganized their surface to adjust to their monolayer conditions (Berthiaume et al., 1996; Zaidel-Bar et al., 2004). Not only cell-cell but also cell-matrix interactions are modified in these conditions (Lesot et al., 1992; Patel et al., 2009). The cell surface plays a central role in determining the ability of cells to react to their environment and to interact with their neighbor. The expression
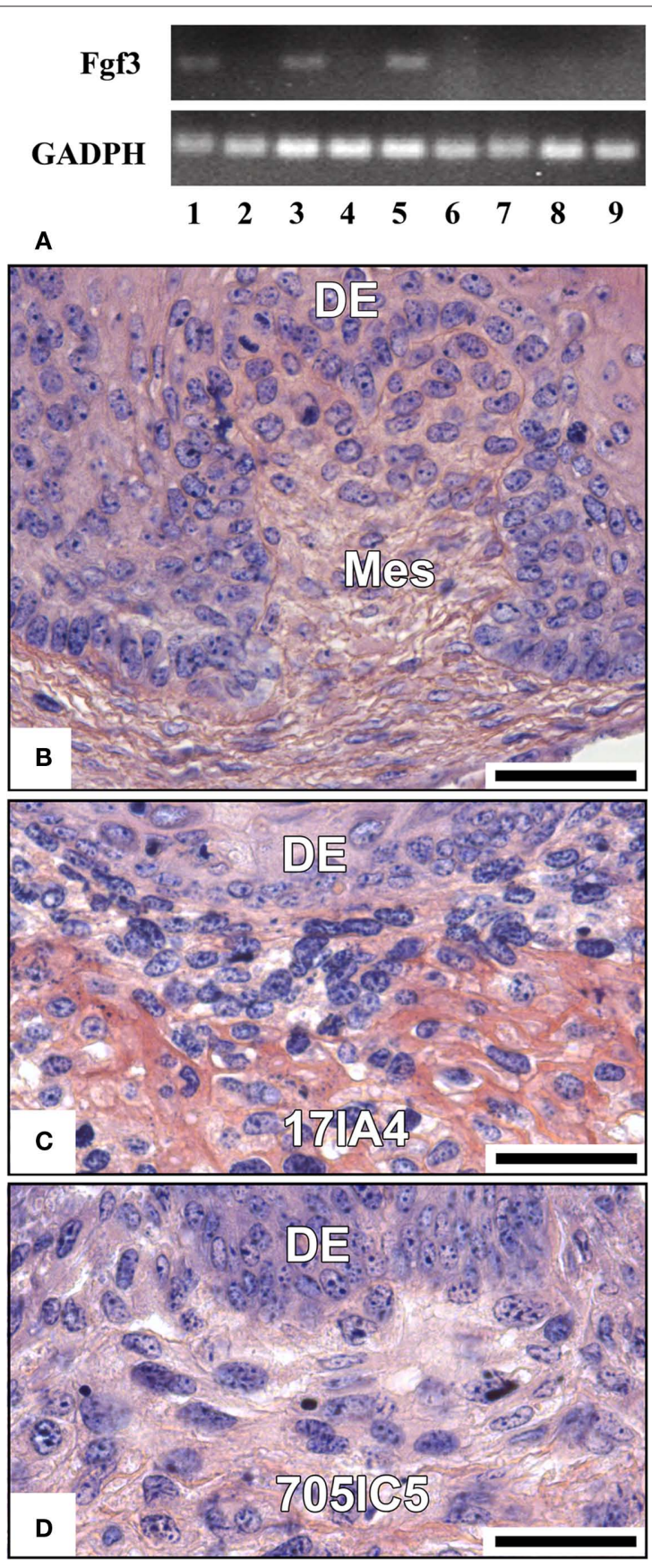

FIGURE 6 | Effect of FGF2 on the expression of Fgf3 (A) and cell potentialities in re-associations (B-D). FGF2 was added to the culture medium of ED14 dental mesenchymal cells or 17IA4 and 705IC5 cells for 1-4 days and its potential effect on Fgf3 was tested by RT-PCR. RT-PCR analysis of the expression of Fgf3 gene in dental mesenchymal cells from ED14 just after dissociation (lane 1), cultured for 1 day (lane 2) or 4 days (lane 4) without FGF2 or cultured in the presence of FGF2 for 1 day (lane 3), or 4 days (lane 5). 17IA4 and 705IC5 dental pulpal clones were also cultured either in the presence of FGF2 for 4 days (lanes 7 and 9 respectively) or without FGF2 (lanes 6 and 8 respectively). GADPH was used as an internal control. Dental mesenchymal cells from ED14 (B), 17IA4 cells (C), and 705IC5 cells (D) were cultured for 4 days in the presence of FGF2 and then for 10 days in re-association with an intact ED14 dental epithelium. DE, dental epithelium; Mes, mesenchyme. Bars $=40 \mu \mathrm{m}$. 
of cell surface markers will have to be investigated to analyze the changes, which may occur from the cap (ED14) to the early bell stage (ED16), and to evaluate how far these could be altered when cells are cultured in monolayer.

\section{CONCLUSION}

Tooth formation occurred when a dental epithelium from ED14 was re-associated with embryonic dental mesenchymal cells from ED14 and ED16. However, this was no longer possible with mesenchymal cells from ED18, probably because at that stage the proportion of cells able to engage in odontogenesis was too small. At ED18, the dental mesenchyme still contains competent cells, as shown after their cloning (Arany et al., 2009). A critical step in the re-association seemed to correspond to the first $24 \mathrm{~h}$, when a dental type of epithelial-mesenchymal junction can be induced or not. The ability of dental mesenchymal cells to engage in tooth

\section{REFERENCES}

Arany, S., Kawagoe, M., and Sugiyama, T. (2009). Application of spontaneously immortalized odontoblast cells in tooth regeneration. Biochem. Biophys. Res. Commun. 381, 84-89.

Balic, A., Aguila, H. L., Caimano, M. J., Francone, V. P., and Mina, M. (2010). Characterization of stem and progenitor cells in the dental pulp of erupted and unerupted murine molars. Bone 46, 1639-1651.

Batouli, S., Miura, M., Brahim, J., Tsutsui, T. W., Fisher, L. W., Gronthos, S., Robey, P. G., and Shi, S. (2003). Comparison of stem-cell-mediated osteogenesis and dentinogenesis. J. Dent. Res. 82, 976-981.

Bei, M., and Maas, R. (1998). FGFs and BMP4 induce both Msxl-independent and Msx1-dependent signaling pathways in early tooth development. Development 125, 4325-4333.

Berthiaume, F., Moghe, P. V., Toner, M., and Yarmush, M. L. (1996). Effect of extracellular matrix topology on cell structure, function, and physiological responsiveness: hepatocytes cultured in a sandwich configuration. FASEB J. 10, 1471-1484.

Bianchi, G., Banfi, A., Mastrogiacomo, M., Notaro, R., Luzzatto, L., Cancedda, R., and Quarto, R. (2003). Ex vivo enrichment of mesenchymal cell progenitors by fibroblast growth factor 2. Exp. Cell Res. 287, 98-105.

Chai, Y., Jiang, X., Ito, Y., Bringas, P. Jr., Han, J., Rowitch, D. H., Soriano, P., McMahon, A. P., and Sucov, H. M. (2000). Fate of the mammalian cranial neural crest during tooth and mandibular morphogenesis. Development 127, 1671-1679.

Challen, G. A., and Little, M. H. (2006). A side order of stem cells: the SP phenotype. Stem Cells 24, 3-12.

Cordeiro, M. M., Dong, Z., Kaneko, T., Zhang, Z., Miyazawa, M., Shi, S.,
Smith, A. J., and Nör, J. E. (2008). Dental pulp tissue engineering with stem cells from exfoliated deciduous teeth. J. Endod. 34, 962-969.

Discher, D. E., Mooney, D. J., and Zandstra, P.W. (2009). Growth factors, matrices, and forces combine and control stem cells. Science 324, 1673-1677.

Duailibi, M. T., Duailibi, S. E., Young, C. S., Bartlett, J. D., Vacanti, J. P., and Yelick, P.C. (2004). Bioengineered teeth from cultured rat tooth bud cells. J. Dent. Res. 83, 523-528.

Govindasamy, V., Ronald, V. S., Totey. S., Din, S. B., Mustafa, W. M., Totey, S., Zakaria, Z., and Bhonde, R. R. (2010). Micromanipulation of culture niche permits long-term expansion of dental pulp stem cells - an economic and commercial angle. In Vitro Cell. Dev. Biol. Anim. 46, 764-773.

Gronthos, S., Mankani, M., Brahim, J., Robey, P. G., and Shi, S. (2000). Postnatal human dental pulp stem cells (DPSCs) in vitro and in vivo. Proc. Natl. Acad. Sci. U.S.A. 97, 13625-13630.

Halfon, S., Abramov, N., Grinblat, B., and Ginis, I. (2011). Markers distinguishing mesenchymal stem cells from fibroblasts are downregulated with passaging. Stem Cells Dev. 20, 53-66.

Honda, M. J., Fong, H., Iwatsuki, S., Sumita, Y., and Sarikaya, M. (2008). Tooth-forming potential in embryonic and postnatal tooth bud cells. Med. Mol. Morphol. 41, 183-192.

Honda, M. J., Nakashima, F., Satomura, K., Shinohara, Y., Tsuchiya, S., Watanabe, N., and Ueda, M. (2007a). Side population cells expressing ABCG2 in human adult dental pulp tissue. Int. Endod. J. 40, 949-958.

Honda, M. J., Tsuchiya, S., Sumita, Y., Sagara, H., and Ueda, M. (2007b). The sequential seeding of epithelial and mesenchymal cells for tissueengineered tooth regeneration. Biomaterials 28, 680-689.

formation was rapidly lost in vitro and was paralleled by the downregulation of Fgf3 expression. However, a pre-culture of these cells in the presence of FGF2 showed that the stimulation of Fgf3 expression in these conditions was not sufficient to recover their potential to participate in tooth formation. A more extensive analysis of the differences between freshly isolated and cultured ED14 mesenchymal cells will have to be performed to better understand at the molecular level what may causally be involved.

\section{ACKNOWLEDGMENTS}

The authors thank Hervé Gegout for the histology and Sasha Dimitrova-Nakov (UMRS-747, Paris Descartes) for her help in the initial phase of this work. This work was funded by the Dental School from Strasbourg University, by the IFRO, and by a grant supporting Strategic Research of Nihon University, School of Dentistry at Matsudo from MEXT, 2008-2012.

Hu, B., Nadiri, A., Bopp-Kuchler, S., Perrin-Schmitt, F., and Lesot, $\mathrm{H}$ (2005). Dental epithelial histomorphogenesis in vitro. J. Dent. Res. 84 521-525.

Hu, B., Nadiri, A., Kuchler-Bopp, S., Perrin-Schmitt, F., Peters, H., and Lesot, H. (2006a). Tissue engineering of tooth crown, root, and periodontium. Tissue Eng. 12, 2069-2075.

Hu, B., Unda, F., Bopp-Kuchler, S. Jimenez, L., Wang, X. J., Haïkel, Y., Wang, S. L., and Lesot, H. (2006b). Bone marrow cells can give rise to ameloblast-like cells. J. Dent. Res. 85, 416-421.

Huang, G. T., Gronthos, S., and Shi, S. (2009). Mesenchymal stem cells derived from dental tissues vs. those from other sources: their biology and role in regenerative medicine. J. Dent. Res. 88, 792-806.

Igarashi, A., Segoshi, K., Sakai, Y., Pan, H., Kanawa, M., Higashi, Y., Sugiyama, M., Nakamura, K., Kurihara, H., Yamaguchi, S., Tsuji, K., Kawamoto, T., and Kato, Y. (2007). Selection of common markers for bone marrow stromal cells from various bones using real-time RT-PCR: effects of passage number and donor age. Tissue Eng. 13, 2405-2417.

Iohara, K., Zheng, L., Ito, M., Ishizaka, R., Nakamura, H., Into, T., Matsushita, K., and Nakashima, M. (2009). Regeneration of dental pulp after pulpotomy by transplantation of CD31(-)/CD146(-) side population cells from a canine tooth. Regen. Med. 4, 377-385.

Iohara, K., Zheng, L., Ito, M., Tomokiyo, A., Matsushita, K., and Nakashima, M. (2006). Side population cells isolated from porcine dental pulp tissue with self-renewal and multipotency for dentinogenesis, chondrogenesis, adipogenesis, and neurogenesis. Stem Cells 24, 2493-2503.
Iwatsuki, S., Honda, M. J., Harada, H., and Ueda, M. (2006). Cell proliferation in teeth reconstructed from dispersed cells of embryonic tooth germs in a three-dimensional scaffold. Eur. J. Oral Sci. 114, 310-317.

Johnnidis, J. B., and Camargo, F. D. (2008). Isolation and functional characterization of side population stem cells. Methods Mol. Biol. 430, 183-193.

Kerkis, I., Kerkis, A., Dozortsev, D., Stukart-Parsons, G. C., Gomes Massironi, S. M., Pereira, L. V., Caplan, A. I., and Cerruti, H. F. (2006). Isolation and characterization of a population of immature dental pulp stem cells expressing OCT- 4 and other embryonic stem cell markers. Cells Tissues Organs 184, 105-116.

Kettunen, P., Laurikkala, J., Itäranta, P., Vainio, S., Itoh, N., and Thesleff, I. (2000). Associations of FGF-3 and FGF-10 with signaling networks regulating tooth morphogenesis. Dev. Dyn. 219, 322-332.

Laino, G., d'Aquino, R., Graziano, A., Lanza, V., Carinci, F., Naro, F., Pirozzi, G., and Papaccio, G. (2005). A new population of human adult dental pulp stem cells: a useful source of living autologous fibrous bone tissue (LAB). J. Bone Miner. Res. 20, 1394-1402.

Lesot, H., Fausser, J. L., Akiyama, S. K., Staub, A., Black, D., Kubler, M. D., and Ruch, J. V. (1992). The carboxyterminal extension of the collagen binding domain of fibronectin mediates interaction with a $165 \mathrm{kDa}$ membrane protein involved in odontoblast differentiation. Differentiation 49, 109-118.

Li, D., Zhou, J., Wang, L., Shin, M. E., Su, P., Lei, X., Kuang, H., Guo, W., Yang, H., Cheng, L., Tanaka, T. S., Leckband, D. E., Reynolds, A. B., Duan, E., and Wang, F. (2010). Integrated biochemical and mechanical signals regulate 
multifaceted human embryonic stem cell functions. J. Cell Biol. 191, 631-644.

Morito, A., Kida, Y., Suzuki, K., Inoue, K., Kuroda, N., Gomi, K., Arai, T., and Sato, T. (2009). Effects of basic fibroblast growth factor on the development of the stem cell properties of human dental pulp cells. Arch. Histol. Cytol. 72, 51-64.

Morizane, A., Darsalia, V., Guloglu, M. O., Hjalt, T., Carta, M., Li, J. Y., and Brundin, P. (2010). A simple method for large-scale generation of dopamine neurons from human embryonic stem cells. J. Neurosci. Res. 88, 3467-3478.

Nait Lechguer,A., Couble, M.L., Labert, N., Kuchler-Bopp, S., Keller, L., Magloire, H., Bleicher, F., and Lesot, H. (2011). Cell differentiation and matrix organization in engineered teeth. J. Dent. Res. 90, doi: $10.1177 / 0022034510391796$. [Epub ahead of print].

Nait Lechguer, A., Kuchler-Bopp, S., Hu, B., Haïkel, Y., and Lesot, H. (2008). Vascularization of engineered teeth. J. Dent. Res. 87, 1138-1143.

Nakao, K., Morita, R., Saji, Y., Ishida, K., Tomita, Y., Ogawa, M., Saitoh, M., Tomooka, Y., and Tsuji, T. (2007). The development of a bioengineered organ germ method. Nat. Methods 4, 227-230.

Nakatomi, M., Wang, X. P., Key, D., Lund, J. J., Turbe-Doan, A., Kist, R., Aw, A.,
Chen, Y., Maas, R. L., and Peters, H. (2010). Genetic interactions between Pax9 and Msx1 regulate lip development and several stages of tooth morphogenesis. Dev. Biol. 340, 438-449.

Ohazama, A., Modino, S. A., Miletich, I., and Sharpe, P. T. (2004). Stem-cellbased tissue engineering of murine teeth. J. Dent. Res. 83, 518-522.

Patel, M., Smith, A. J., Sloan, A. J., Smith, G., and Cooper, P. R. (2009). Phenotype and behaviour of dental pulp cells during expansion culture. Arch. Oral Biol. 54, 898-908.

Priam, F., Ronco, V., Locker, M., Bourd, K., Bonnefoix, M., Duchêne, T., Bitard, J., Wurtz, T., Kellermann, O., Goldberg, M., and Poliard, A. (2005). New cellular models for tracking the odontoblast phenotype. Arch. Oral Biol. 50, 271-277.

Rothova, M., Feng, J., Sharpe, P. T., Peterkova, R., and Tucker, A. S. (2011). Contribution of mesoderm to the developing dental papilla. Int. J. Dev. Biol. 55, 59-64.

Ruch, J. V., and Karcher-Djuricic, V. (1971). Mise en evidence d'un role spécifique de l'épithélium adamantin dans la différenciation et le maintien des odontoblastes. Annales d'Embryologie et de Morphogenèse 4, 359-356.

Russo, L. G., Maharajan, P., and Maharajan, V. (1998). Basic fibrob- last growth factor (FGF-2) in mouse tooth morphogenesis. Growth Factors 15, 125-133.

Sakai, V. T., Zhang, Z., Dong, Z., Neiva, K. G., Machado, M. A., Shi, S., Santos, C. F., and Nör, J. E. (2010). SHED differentiate into functional odontoblasts and endothelium. J. Dent. Res. 89, 791-796.

Tsuboi, T., Mizutani, S., Nakano, M., Hirukawa, K., and Togari, A. (2003). Fgf-2 regulates enamel and dentin formation in mouse tooth germ. Calcif. Tissue Int. 73, 496-501.

Unda, F. J., Martín, A., Hilario, E., BègueKirn, C., Ruch, J. V., and Aréchaga, J. (2000). Dissection of the odontoblast differentiation process in vitro by a combination of FGF1, FGF2, and TGFbeta1. Dev. Dyn. 218, 480-489.

Wagner, W., Ho, A. D., and Zenke, M. (2010). Different facets of aging in human mesenchymal stem cells. Tissue Eng. 16, 445-453.

Yen, A. H., and Sharpe, P. T. (2008). Stem cells and tooth tissue engineering. Cell Tissue Res. 331, 359-372.

Young, C. S., Terada, S., Vacanti, J. P., Honda, M., Bartlett, J. D., and Yelick, P. C. (2002). Tissue engineering of complex tooth structures on biodegradable polymer scaffolds. J. Dent. Res. 81, 695-700.

Yu, J., He, H., Tang, C., Zhang, G., Li, Y., Wang, R., Shi, J., and Jin, Y.
(2010). Differentiation potential of STRO- 1+ dental pulp stem cells changes during cell passaging. $B M C$ Cell Biol. 11, 32.

Zaidel-Bar, R., Cohen, M., Addadi, L., and Geiger, B. (2004). Hierarchical assembly of cell-matrix adhesion complexes. Biochem. Soc. Trans. 32, 416-420.

Conflict of Interest Statement: The authors declare that the research was conducted in the absence of any commercial or financial relationships that could be construed as a potential conflict of interest.

Received: 17 December 2010; accepted: 17 February 2011; published online: 04 March 2011.

Citation: Keller L, Kuchler-Bopp S, Mendoza SA, Poliard A and Lesot H (2011) Tooth engineering: searching for dental mesenchymal cells sources. Front. Physio. 2:7. doi: 10.3389/fphys.2011.00007

This article was submitted to Frontiers in Craniofacial Biology, a specialty of Frontiers in Physiology.

Copyright (C) 2011 Keller, Kuchler-Bopp, Mendoza, Poliard and Lesot. This is an open-access article subject to an exclusive license agreement between the authors and Frontiers Media SA, which permits unrestricted use, distribution, and reproduction in any medium, provided the original authors and source are credited. 